\title{
Changing messages about place of birth in Mother and Baby magazine between 1956 and 1992
}

Key words: history; home birth; hospital birth; magazines; media

\section{Highlights:}

- The content of Mother and Baby magazine reflected the move from home to hospital birth between 1956 and 1992

- During this time the content changed from promoting a social model of birth to a medicalised one.

- The magazine used written content, design and layout to promote hospital birth.

- Home birth was still discussed in supportive terms in the magazine across the period, reflecting a plurality of discourse

- The study found that during this time the content of the magazine both shaped and reflected women's choices in maternity care.

\section{Abstract:}

Objective: This paper explores changing messages about place of birth offered to women by Mother and Baby magazine, a UK publication aimed at a general readership

Design: The research uses an historical perspective to explore changing messages about place of birth in Mother and Baby magazine between 1956-1992. It analyses the content and medium of the magazine through a narrative and semiotic approach.

Setting: The UK between the mid-1950s and 1990s. The period was a time of significant change in the maternity services, at both a philosophical and organisational level with a move towards hospital rather than home birth and a dominant discourse which privileged medical models of care over social ones.

Participants: Producers and consumers of Mother and Baby magazine

Findings: Mother and Baby moved from an assumption of home birth to a focus on hospital birth, reflecting national changes in policy. The magazine moved from a social to a risk focused medical view of birth, with an emphasis on the safety of the baby and the sacrifice of the mother. These changes can be traced through both the organisation and the language of content between 1956 and 1992. However, home birth was always offered to readers as a viable, if increasingly niche, option. This reflected the magazine's need to appeal to its readers as consumers; both in consumption of the magazine and of maternity care.

Conclusions: The evidence suggests that Mother and Baby magazine mirrored elements of the prevailing policy discourse around place of birth. However, it always gave space to other narratives. In doing so it reminds us of the complexity about how messages about labour and birth are told and received. It gives insight into ways in which the media lead and reflect change and the impact this might have on decision making by women.

\section{Introduction and literature review:}

One of the main features of maternity care in the UK in the second half of the twentieth century is the transition of place of birth from home to hospital (McIntosh 2012). This pattern is replicated internationally (Leavitt 1986; Wertz and Wertz 1989; De Brouwere et al 2002; Fealy 2005; 
Bourgeault 2006). Traditionally this has been presented as an obstetrically driven change, supported by policy makers (Tew 1985; Oakley 1980). Women have been characterised as the victims of a masculine, medicalised power grab (Oakley 1980, Donnison 1988). More recently this viewpoint has been critiqued by those exploring women's voices and experiences across the period (Davis 2012). It has been argued that in fact women did have agency, and there is evidence that some demanded hospital birth and its high tech accoutrements (McIntosh 2012). Over the last 25 years there has been an acceptance that that home birth is a viable option for many women (Birthplace 2011), and policy documents have reflected this shift (DoH 1993 DH 2007, NHS England 2016). Despite this, proportions of home birth remain generally low across the country with a national average of $2.3 \%$ (ONS 2016). Appreciating the nuances of how and why hospital birth came to be the norm may help in contextualising these shifts and in developing meaningful contemporary policy to support women in their decision making about where to give birth. This paper addresses this through a critical exploration of the UK women's pregnancy magazine Mother and Baby.

Women access information about pregnancy and birth through a variety of different sources. Health professionals often assume that their voice is heeded as particularly authoritative, but women have always utilised friends and family, printed material including books and magazines and more recently television and the internet (Davis 2012). There is a body of sociological work exploring the role and influence of women's magazines in general (Ferguson 1983; Winship 1987; Ballaster et al 1991; McCraken 1993; Braithwaite 1995; Hermes 1995; Gauntlett et al 2008) and a strand of midwifery research which considers the influence particularly of new media such as the internet (Kennedy et al 2009; Kline 2007; Bick 2010; Song et al 2012; Luce et al 2016). Work on women's magazines developed in 1970s as part of a growing academic interest in media studies (Curran 2002). It used a primarily feminist lens to explore the content and message of glossy magazines in particular (Ferguson 1983; Winship 1987; McCraken 1993; Hermes 1995). A trajectory from a conservative moralistic tone focussing on domesticity in the 1950s to a much more open style from the late 1960s and into the 1970s was posited. Despite this change of tone, it has been argued that magazines remain in thrall to their advertisers and therefore to women as consumers, a consideration which has been seen negatively by researchers (Ferguson 1983). More recently it has been argued however, that readers of magazines have agency and approach their reading with a level of criticality; messages from editorials and advertisements are not necessarily swallowed whole by readers (Hermes 1995). Media theory draws attention to the way that this agency is seen through the act of encoding and decoding messages and the moment of the text (Hall 1980); in other words the underlying principles of a given article (for example a belief that hospital birth is safer than home birth), the form of those principles (the way language used, the pictures used) and the reception by the reader; who may agree or disagree with text.

This layered reading has been absent from contemporary work, often by midwives, exploring the impact of media on women's views of pregnancy and birth (Luce et al 2016). Studies have considered the intersection between media representation and practice around elective caesareans and breech births from the late 1990s onwards (Weaver 2004; Campo-Engelstein et al 2015; Petrovska et al 2017). The majority of this work has focussed on newspapers, television and the internet with no attention being paid to magazines. There is very little acknowledgement that women will bring their own knowledge and beliefs to their use of media (Song 2012; Maclean 2014). Midwife authors have demonstrated an implicit belief that women should get their information from 
midwives, and this colours their interpretation of the media they are studying. Work on 'risk' and decision making by women around birth has privileged media as a source of information which supports this risk driven view of birth and information giving around this (Seale 2004).

This paper brings together these two strands of research - one on women's magazines in general, and one on media around pregnancy and birth - to offer a more nuanced exploration of how birth has been depicted. There is no published work which considers ways in which media and women engaged around the move from home to hospital birth in the 1960s and 1970s. This paper explores patterns of care between the 1950s and 1990s through changing messages about place of birth offered to women by Mother and Baby magazine, a UK magazine aimed at a general readership of women and available through newsagents and supermarkets. In doing so it seeks to highlight the nuanced and complex place of media in both influencing and reflecting ideas about birth.

The magazine was launched in 1956 explaining to readers that '...it has been created for you; to help you in the problems that beset mothers and mother to be; to bring you news and views from other mothers, from the medical profession and from child experts who want you to seek guidance wherever it is needed.' (Jan 1956 p.4). The intention was to offer support, friendship and expertise. The implication was that mothers would receive authoritative advice they could trust in their journey to become 'the perfect mother of the perfect baby.' (Jan 1956 p.4). Inevitably the magazine mutated over time; out went the romantic fiction and puff pieces about film stars, and in came discussion about contraception and, by the late 1960s, abortion, single parenthood and working mothers. These themes reflected broader societal changes for women although core themes of knitting, cooking and beauty remained remarkably resilient. 1992 is taken as the end point of the study as it coincides with debate around the state of the maternity service including the place of birth, culminating in the publication of the Changing Childbirth report in 1993 (DoH 1993). This report arguably changed rhetoric, if not always practice, by suggesting that hospital was not necessarily the best place for women to birth (McIntosh and Hunter 2014).

\section{Background:}

The broad features of changes in the organisation of maternity in the UK between the 1950s and 1990s are well documented. Despite the creation in 1948 of the National Health Service, maternity services remained fragmented in a tripartite structure with women receiving care from hospitals, general practitioners, and local authority welfare clinics and district midwives (McIntosh 2012). The system came under scrutiny in 1959 but was not altered until 1974 when all local authority services were brought under the auspices of local hospital boards. These organisational changes reflected developing policy around the desirable place of birth. The 1959 Cranbrook report (DoH 1959)had argued that there should be hospital beds available for $75 \%$ of births. This was followed in 1970 by the Peel report (DoH 1970) which argued that on the grounds of safety provision should be made for all women to give birth in hospital.

Running concurrently with the hospitalisation of birth was a focus on technologies both antenatally and during labour. Regional anaesthesia, ultrasound scanning, CTG monitoring and chemical methods of induction of labour were all developed in the 1960s, becoming increasing prominent in the 1970 s and virtually routine by the 1980s. They were technologies which required a hospital setting and both developed from and fed into a growing sense that pregnancy and birth were risky 
processes (Cartwright 1979; Oakley 1981). This viewpoint culminated in the Short report of 1980 (DoH 1980) which argued that a labour room should be analogous to an intensive care unit such were the potential risks of birth. By the early 1990s this rhetoric was increasingly challenged by consumer groups and researchers. When the precursor to Changing Childbirth, the Winterton report, was published in 1992 it argued that there was no evidence to say that home birth was unsafe and that a blanket policy of hospital birth 'cannot be justified on the grounds of safety.' (DoH 1992 xii)

It is unlikely that most women read government documents about organisation of care. Instead they got their information as they had always done, from friends and family and from written material (Mechling 1975; Davis 2012). Books had long been a feature of advice for women about pregnancy and birth. Targeted magazines were, however, a new departure. Women's magazines had gone through a period of huge growth and development in the inter war period, reflecting changes in women's lives and particularly in their spending power (Braithwaite 1995). They tended to focus on domestic and personal agendas, with cooking, sewing, fashion, beauty and childcare featuring very prominently. Magazines such as Woman and Woman's Weekly achieved huge mass circulation in the 1930s which continued into the 1950s (Braithwaite 1995). They occasionally featured pregnancy, but their focus was on childrearing rather than birth. As such there was a gap in the market filled in 1956 with the launch of Mother and Baby magazine. Initially, as with other women's magazines, birth was discussed in only the broadest terms and concentration was primarily on child rearing. The first article about labour appeared six months after Mother and Baby started. It was brisk in tone; 'the degree of pain varies as does the time of labour but it is an incontrovertible fact that they are never as bad as one anticipates... (June 1956 p.38). It was not until 1971 that the first picture of a birth was printed. By 1970s 'personal' stories were heavily used to discuss different types of birth experience, signalling the beginning of a much more pluralistic, and individualistic, view of birth which continued into the early 1990s.

As the wide-ranging literature review above indicates, research around pregnancy and birth must necessarily be broad in the approaches it takes. This is because maternity is both a biological, social, historical and geographical construction. For this reason work has been undertaken by, among others, sociologists, anthropologists and philosophers as well as clinicians. Increasingly historical methods are used, not as a simple lesson in how things have changed, but to interrogate different aspects of parenting over time. This paper draws on historical methods primarily to situate the message offered by Mother and Baby magazine.

\section{Methodology and methods:}

The paper draws specifically on the disciplines of media history (Curran 2002; Bailey 2009) and of the social history of medicine (Waddington 2011). In doing so it incorporates elements of media studies and media theory (Bignell 1997) to consider the medium and message of the magazine. This triangulation of disciplines allows for the fullest reading of the material and helps in ensuring reflexivity in relation to the research. This is further aided by using a variety of sources to back up and strengthen the interpretation. In this case, the use of wider secondary and primary sources of historical evidence (such as oral history testimonies, policy data and other contemporary material), although not foregrounded in this paper, strengthen the validity of the interpretations. As with any discipline, there are always multiple possible readings; the challenge for the historian is to be aware 
of the nuances of interpretation in a given context (Bloch 1954; Carr 1961) and to strive to maintain reflexivity and criticality throughout the process (Gazi 2010; MacKenzie 2015).

A complete run of Mother and Baby magazine is available in hard copy at the British Library (catalogue number pp.2707.ici). It has been published monthly since January 1956. There is no cumulative index. Every edition was read by the author with notes taken contemporaneously and photographs taken of many pieces. This dual approach allowed for a deeper reading of material as immediate responses were jotted down at the time, and were followed by a slower re-read allowing for concentration on different elements. Although the magazines covered a wide variety of topics, attention was limited to material relating to pregnancy and birth. This accounted for approximately $20 \%$ of early magazines, rising to approximately $75 \%$ by the 1990 s. This paper is part of a larger study and presents only the material which relates specifically to place of birth.

An awareness of media theory allows for a nuanced reading of the material available. The analysis of content is broadly narrative focusing on editorials and articles in particular (Gillespie 2006).

Alongside this is a strand of semiotic analysis, taken from media theory, which considers the medium of the messages offered including the use of language, pictures and graphics (Bignell 1997). Hall's (1980) concept of encoding/decoding and the moment of the text is used to guide the interpretation.

The main areas highlighted by analysis were:

The changing message

Telling the story

The growth of the 'consumer'

This paper focuses on these broad areas in relation to changing messages about the place of birth in Mother and Baby.

\section{Findings and discussion}

\section{The changing message}

In essence Mother and Baby magazine moved from promoting home birth in the 1950s to hospital birth in 1990s with change occurring particularly in the 1970s. There was however never a point when a specific place of birth was taken for granted or assumed; it was always a contested space and the messages offered by the magazine were never linear. Home birth continued to be discussed as an option throughout the period, although the language and layout of articles made clear that it was a niche option from the mid-1970s onwards.

The change from promulgation of home to that of hospital occurred because the balance of what was seen as the most important element of birth tipped decisively across the period from social considerations to the foregrounding of a risk agenda. Initially the social side of birth was stressed, with the fact that it was basically safe taken for granted. This meant that home was seen as the logical place for birth; women were the centre of attention, and everything was arranged around them (September $1956 \mathrm{p44}$ ). In answer to a query from a reader about where to have a first baby 
the answer from the magazine's 'Matron' (an anonymous dispenser of advice) was a brisk 'I had two of my four children at home and it's much more fun!' (March 1959 p.6). In contrast hospitals were recommended as 'efficient' places. In response to a letter from a woman who had had a long labour in hospital and a forceps delivery, 'Matron' replied 'the second baby will be easier and home is best.' (Jan 1962 p4) Well into the 1960s hospital birth was painted in a very negative light with the comment that 'It is doubtful though, whether hospitals are really ideal places for such a natural event as human birth...' (June 1965 p12). The drawbacks were then listed; loneliness, rigidity of routines, risk of infection and separation of mothers and babies. However another note began to creep into the discussion around place of birth and that was around risk in its baldest sense. In the article highlighted above, the drawbacks laid out were ultimately characterised as 'minor' and readers reminded that many mothers and babies owed their lives to hospital births.

This concept of risk and, concomitantly, of medicalisation increasingly appeared in Mother and Baby as justifications for hospital birth, echoing wider official policy. The social importance of the birth environment was subsumed into a risk discourse. By 1968 a primigravida wanting a home birth was 'most strongly' advised to have a hospital birth. Furthermore 'A lovely baby is such a splendid reward for doing something you don't like.' (November 1968 p9). This demonstrates an uncritical acceptance of official beliefs that hospital was the safest place of birth, and a growing emphasis on the physical safety of the foetus over anything the mother might experience. Neither of these assumptions were ever questioned by the magazine. It also reminds us, however, that women were still interested in home birth, and the magazine had to take its readers into account, even if only to warn them about what it saw as the risks of their choice.

Three years later the Mother and Baby interpreted the Peel report (November 1971 p20) for its readers. The report had stated that hospital beds should be available for all women, in the belief that it was the 'safest' environment for birth. The magazine had already begun to alert readers to the perceived connection between hospital birth and safety. It had done this primarily through the medium of authority; the doctors and 'Matrons' (who the readership would be expected to assume was a midwife) who wrote for it. The magazine dealt in broad brush approaches rather then evidence. However the article on the Peel report had to accept that women might still prefer an alternative reading of birth, in which it was safe and home was the best place, and noted that the call for more hospital births would shock those who thought hospital was only for abnormal situations. However Mother and Baby did not pursue this critique of the Report but instead explained how the system would work, and how to ensure a hospital birth. In doing so the magazine reflected not the tension between social and medical models of birth but that of geography and provision. Although hospital birth was now lauded, many women still had to have a home birth because, particularly in cities such as Nottingham or rural areas like Suffolk, there were not enough institutional beds available (McIntosh 2012). The article strongly suggested that home birth was no longer an acceptable choice and women should not be forced into it by lack of provision. In do so it pushed the hospital agenda, whilst acknowledging an undercurrent of variance.

By the end of the 1970s, the official rhetoric about hospital birth and home birth seemed to have been internalised by Mother and Baby and processed for its readers. The beliefs of the Short report that birth was a medical emergency were borne out by a personal story from December 1980 entitled 'When things went wrong'. The article began with a stand first explaining that the writer 
was 'grateful' that her two children were born in hospital with the help of 'highly skilled medical experts.' The first birth was a forceps delivery with the payoff that 'I dread to think what may have happened if I had determined to have my baby at home.' With the second birth, haemorrhage occurred on day 6 postnatally, whilst the writer was still in hospital. 'I am horrified to think of the consequence had my second child been a home confinement.' It seems that it was not enough to tell the story; sides had to be taken and the potential consequences of home birth highlighted in terms of ultimate risks.

However the way Mother and Baby depicted the place of birth was more layered than these stories might suggest and the tensions between birth as a social event and a medical emergency remained evident in the magazine. This is demonstrated by a series of articles during 1976. In February it was commented that home birth is better than hospital on social grounds and this was followed in March by a description of an uncomplicated home birth. In April an article on labour told readers that when their waters broke they should call their midwife or go to hospital. This implied that community midwife supported home birth was still an option. Three months later a selection of letters in favour of home birth was printed. The magazine's resident obstetrician, Dr Alexander Gunn, had the last word in December commenting that home birth was 'definitely not' safer than hospital. This juxtaposition of views was illustrated even more starkly in October 1979 with a story about a calm home birth, surrounded by boxed sections of text describing how to achieve a home birth, and how to join the National Childbirth Trust (NCT). Next to these was another boxed section by Gunn, explaining that doctors were biased against home birth because technology and hospital made it safer. Gunn argued that it was not right to return to the 'olden days' of home birth and women had to accept the lack of choice, strict regimes and 'subjugation to technology' to save mother and baby. The writing is striking not for its power but for its defensiveness. There is no sense of the positivity of a choice to birth in hospital, instead the decision is couched in the language of ultimate risk; that of death. A decade later the same issues can still be seen. An article entitled 'The joy of homebirth' appeared in November 1989 with four reader's experiences. The homeliness of the situation was emphasised in sub headings: 'eating a chip butty at 8pm - at 8.13 Tristan arrived' 'daughter born as lambs were bleating the fields'. There were notes of caution also apparent '...enjoyed her home birth but it turned into hard work' and a 'difficult breech delivery...' Dr Gunn was given space to comment. His view was that that stories were 'marvellous to read', but he reminded readers to remember things can go wrong and 'disasters can occur'. Again this gave readers the clear steer that however; 'nice' home birth might be it was not a risk worth taking.

\section{Telling the story}

The changing messages around place of birth were articulated not just through the content of articles but also the way in which information and ideas were presented. Two linked articles published in November and December 1973 illustrate the power of the medium to support the message. The November article entitled 'Having a baby at home' was presented in a lower case sans serif font of the type used for children's books and surrounded by simple flower motifs, suggesting a domestic and homely quality which emphasized the social space of birth at home. The article began by reminding the reader that hospital birth was vital where safety is an issue, but that most births were normal. In this way it played into the dominant discourse of risk and safety, whilst also acknowledging the social model of birth. The sub-headings bore out the social model; 'comfort and peace' 'no rush' and 'easy breast-feeding'. There was no discussion of the birth but there was a 
large photo illustration; a close up of a smiling mother and baby. The article about hospital birth which appeared the following month included two pictures; the first was a very peaceful looking ward with vases of flowers, mothers reading in bed and no visible babies. The second photo was of a woman delivering; her legs held apart by masked and gowned attendants and her face a grimace. The juxtaposition of these two images reminded the reader of the discomfort and sacrifice of hospital birth, but also presented the end result which was a calm well-ordered environment. The title of the piece 'Why you should have your baby in hospital' had a spiky upper-case font and black border, implying both seriousness, and with the black border, the possibility of death. The subheadings were 'statistics of survival' 'who is at risk? 'and 'discomforts of hospital.' The language confirmed that women cannot be assumed to birth safely - they must 'prove it'. The undercurrent was a reminder to women to be afraid. This allowed the article to make a virtue of the sacrifice involved in choosing hospital; 'Lack of privacy, emotional upset, failure to sympathise with the individual, parting from the family, husband and other children, and the conformity to rules and regulations are part of the price'. It was even pointed out that risks of infection were greater and breast feeding harder to achieve; but that they were all a price worth paying. In semiotic terms this seems to go against the grain; hospital is not presented as a positive choice. The message being presented was that hospital birth was not in social terms desirable; the way it was coded however suggested that its very undesirability made the reasons for it more important. It aligned clearly with the other dominant theme of motherhood presented by the magazine; sacrifice. Mothers were required to sacrifice their own comfort and health in order to safeguard the baby. What cannot be unpicked is how women decoded the message on offer; it is possible that some women would have seen this dominant discourse in oppositional terms, giving them the ammunition to continue to access home birth.

\section{Growth of the consumer:}

The reasons that the deviant discourse around home birth, seen in the example above, continued to run through the dominant discourse of hospital birth is partly to do with the function of magazines. Magazines lived and died by their circulation figures, and by the advertising they could attract (Braithwaite 1995). These issues in turn meant that one point of view could never be assumed; in order to draw in the widest readership the magazine had to give space to different ideas. Although the circulation figures for Mother and Baby are not known for this period, the evidence of content suggests a socially broad readership (a regular feature of the magazine from the 1960s to the 1990s was the 'meet a mum' page whereby women wrote in with personal details including employment, address and parity, in order to make contact with others in their area. Those writing in represented a cross-section of age, class and experience). There is therefore a pragmatism about the stories told and ideas developed. To decry home birth totally would have alienated possibly a small minority of women, but these were often the vocal ones who belonged to the NCT and the Association for Improvements in the Maternity Services (AIMS) and had middle class spending power to appeal to publishers and advertisers. The need to appeal to a cross-section of readers meant that there was always a place for positive representations of home birth. Importantly this plurality of stories fitted the other growth narrative of the period; the idea of the 'patient' as 'consumer' (Hilton 2003). This meant that the supremacy of a particular type of birth could not just be assumed; it had to be sold to women, who might, increasingly choose a different path. This reading is in opposition to earlier sociologists' work on women's magazines which assumed that a focus on circulation and advertising 
revenue diminished women, making them passive recipients of whatever the magazine was offering (Winship 1987; McCracken 1993).

The consumption agenda can be seen in the early 1960s when the magazine reprinted an article from the feminist slanted Time and Tide magazine critiquing the regimentation and lack of comfort of hospitals with a sub-heading labelled 'hospital tyranny' (April $1961 \mathrm{p} 4$ ). The sense of shock evident in the writing is palpable with women urged to make their voices heard so that hospitals could be improved. This was the rhetoric which allowed consumer groups such as the NCT and the AIMS to flourish. The two organisations feature very heavily in Mother and Baby throughout the period under discussion, first as levers to push for improved hospital birth, and later to support alternative narratives of birth including home birth. As we have seen above, commercial pressures were a significant driver of magazine content, and in giving platforms for the NCT and AIMS Mother and Baby continued to appeal to a cross-section of potential readers. The concept of birth as a unique and individual consumer event can be seen also in the growth of the 'birth story' in the magazine. This began in the late 1960s with a move from anonymous authoritative pieces, to named authors (including a roster of 'experts') and true life stories from women. By the late 1970s these formed a prominent part of features about pregnancy and birth. The most common layout was that of an article written by a journalist, with personal stories illustrating different experiences, and the 'expert' commentary by a doctor. It is noteworthy that despite the continued space given to home birth narratives, the expert was always a doctor who invariably took the view that a successful home birth was just extremely good luck, whereas a difficult hospital birth represented a triumph for science.

The consumer voice meant that although by the late 1980s home birth rates were at historic lows of around $1 \%$ of births (Mcfarlane et al 2000), discussion of them as an option did not disappear from Mother and Baby. Advice about 'how to have a home birth' (June 88 p21) included getting your husband on side, being polite to staff, understanding your risk factors... and knowing when to bow to the inevitable hospital birth. Such articles used the language of risk and the idea that birth in hospital was the ultimate fail safe. Even within the consumer discourse choices about places of birth were not equally weighted despite the fact that they were presented as a supposedly neutral 'menu' of options. An article in November 1988 was presented under the heading 'Yes, you do have a choice'. Within this, hospital was characterised as good for high tech care, but leaving women feeling treated like cattle. In contrast GPs were 'homely' but not 'expert' and home births chosen by 'only one per cent of women...'. Two years later 'Getting the birth you want' repeated the idea. In both cases the 'menu' of options clearly suggests a hierarchy with hospital consultant unit at the top, followed by GP unit, shared care, DOMINO schemes, home birth and private hospital. For home birth the onus was on the woman to write to their GP, supervisor of midwives and health authority to ask for a home birth; the consumer had to be savvy and tenacious. This implies acceptance that the possibility of home birth still existed, although it could be argued that continued discussion of options was aspirational rather than realistic for most women. However it also highlights a continued plurality of debate around place of birth.

\section{Conclusion}

National policy towards the place of birth underwent significant change from the 1950s to the early 1990s. In common with this Mother and Baby moved from an assumption of home to a focus on 
hospital birth and reflected these changes in both the organisation and the language of content. The thread running through the magazine is that of sacrifice and duty on the part of the mother in relation to the place of birth, and the growing centrality of a risk discourse which elided safety with medicalisation, articles across the period did not demonstrate a clear-cut linearity from home to hospital. Home birth never disappeared from the pages, and it was always seen as a viable, if niche option. This duality of perspective and the complexities it throws up can be seen in the use of the medium of the magazine. As well as subliminal signalling through text and illustration the magazine relied on a mixture of anecdote, evidence, opinion and 'authority' to make its points. This muddled the narrative, but also allowed space for competing ideas. This was partly because there was always a need to appeal to a cross-section of readers. As a result of ideas about the public as consumers of healthcare rather than simply passive recipients, the language and ideas presented about place of birth were complex and at times contradictory. Hospital birth had to be sold as an idea; its superiority could not be assumed. This sale was usually done by foregrounding beliefs about safety, primarily the safety of the baby. In doing so Mother and Baby drew on ideas of maternal sacrifice to justify hospital birth, making a virtue of the discomfort and risks to the mother. The magazine used authoritative opinion and anecdote to support this point of view, reflecting the fact that there was no real evidence to underpin it. From a social perspective of birth however hospitals were very much condemned and this did not change over the period. Women as consumers were urged to complain about conditions in hospitals. Home birth never completely disappeared from the magazine, despite the fact that home birth rates were vanishingly small by the early $1980 \mathrm{~s}$. It always continued to be presented as a realistic choice, albeit one that required tenacity on the part of the individual to achieve.

As with any research, historical enquiry raises as many questions as it answers. Among the limitations of this work is that it looks only at the transmission of messages about place of birth, and the way that Mother and Baby adapted to changing policy and ideas. There is no attempt to explore how women chose to decode the messages they received, and how they used them to develop their own understanding of pregnancy and birth. The research also applies only to the UK in the second half of the twentieth century. Sources of information and support for women about birth have become much more varied with the advent of the internet in particular. However this paper does help to contextualise our understanding of how the changing message about place of birth was told to women. By using elements of media theory it reminds us of the complexity of the message, and the continued space given to alternative narratives. This in turn can help to understand the nuances of the beliefs women hold and the decisions they make around birth as well as the influence of the media both in shaping and reflecting discourse.

Bailey M ed 2009 Narrating media history. Routledge: London

Ballaster R, Beetham M, Frazer L, Hebron S 1991 Women's worlds: ideology, femininity and the woman's magazines. Palgrave Macmillian: Basingstoke

Bick D 2010 Media portrayal of birth and the consequences of misinformation. Midwifery 26: 147-8

Bignell J 1997 Media semiotics; an introduction. Manchester University Press, Manchester

Birthplace in England Collaborative Group 2011. Perinatal and maternal outcomes by planned place of birth for healthy women with low risk pregnancies: the Birthplace in England national prospective cohort study. BMJ $25^{\text {th }}$ November. http://www.bmi.com/content/343/bmi.d7400 [Accessed 7

March 2017]. 
Bloch m (1954) The historians craft. Manchester University Press: Manchester

Bourgeault, I. L. 2006 Push! The Struggle for Midwifery in Ontario, Quebec: McGill-Queens University Press

Braithwaite B 1995 Women's magazines: the first 300 years. Peter Owen: London

Campo-Engelstein L, Howland LE, Parker WM, and Burcher P 2015 Scheduling the stork: media portrayals of women's' and physicians' reasons for elective caesarean delivery, Birth, 42 (2); 181-88

Carr, E. H. 1961, reprinted 1981 What is History?, Harmondsworth: Pelican Books

Cartwright A 1979 The dignity of labour: a study of childbearing and induction. Tavistock

Publications: London

Curran J 2002 Media and the making of British society; c.1700-2000. Media History 8 (2): 135-154

Gillespie M 2006 Narrative analysis. chapter 3 in Gillespie M and Toynbee J Analysing media texts.

Open University Press: Maidenhead

Davis A 2012 Modern motherhood: women and family in England 1945-2000. Manchester university

Press: Manchester

De Brouwere, V., Tonglet, R. and Van Lerberghe, W. 2002 'Strategies for reducing maternal mortality in developing countries: what can we learn from the history of the industrialized West?', Tropical Medicine and International Health, 3(10), 771-782

DoH Department of Health 1980 Perinatal and neonatal mortality. Second Report from the Social Services Committee 1979-80 (Short Report). London: HMSO.

DoH Department of Health 1992 Health Committee Second Report: Maternity Services (Winterton Report), London: HMSO

DoH Department of Health 1993 Report of the Expert Maternity Group: Changing Childbirth (Cumberlege Report), London: HMSO

DH Department of Health 2007 Maternity Matters. HMSO: London

Donnison, J. 1988 Midwives and Medical Men: A History of The Struggle for the Control of Childbirth, $2^{\text {nd }}$ edn, London: Historical Publications

Fealy, G.M. (ed.) 2005 Care to Remember: Nursing and Midwifery in Ireland, Cork: Mercier Press Ferguson M 1983 Forever feminine: Women's magazines and the cult of femininity. Heinemann: London

Gauntlett D 2008 Media, gender and identity: an introduction. $2^{\text {nd }}$ edition Routledge: London Hall S 1980 'Encoding/ decoding', chapter 10 in Hall S, Hobson D, Lowe A, Wills P 1980 Culture, media and language, Hutchinson University library

Gazi E 2010 History between reflectivity and critique: introduction, Historein, 105-9

Hermes J 1995 Reading women's magazines: An analysis of everyday media use. Polity Press:

Cambridge

Hilton M 2003 Consumerism in twentieth century Britain. Cambridge University Press: Cambridge Kennedy HP, Nardini K, McLeod-Waldo R, Ennis L 2009 Top-selling childbirth advice books: a discourse analysis. Birth 36 (4): 318-324

Kline K 2007 Midwife attended births in prime-time television: craziness, controlling bitches and ultimate capitulation Women and Language 30 (1) 20-29

Leavitt JW 1986 Brought to Bed: Childbearing in America, 1750-1950, Oxford: Oxford University Press

Luce A, Cash M, Hundley V, Cheyne H, van Teijlingen E, Angell C 2016 'Is realistic?' the portrayal of pregnancy and childbirth in the media. BMC Pregnancy and Childbirth 16 (40) DOI: 10.1186/s12884016-0827-x 
Macfarlane, A., Mugford, M., Henderson, J., Furtado, A., Stevens, J. and Dunn, A. 2000 Birth Counts: Statistics of Pregnancy and Childbirth, Volume 2 - Tables, The Stationary Office: London

Maclean E 2014 What to expect when you're expecting? Representations of birth in British newspapers. British Journal Midwifery 22 (8): 580-588

McCraken E 1993 Decoding Women's magazines. Macmillian: London McIntosh T 2012 A social history of maternity care Routledge: Abingdon

McIntosh, T and Hunter, B (2014) ' "Unfinished business"? Reflections on Changing Childbirth twenty years on'. Midwifery 30: 279-81

McIntyre MJ, Francis K, Chapman Y 2011 Shaping public opinion on the issue of childbirth: a critical analysis of articles published in an Australian newspaper. BMC Pregnancy and Childbirth 11 (47) DOI: 10.1186/1471-11-47

McKenzie L 2015 Getting by, Polity Press: Cambridge

Mechling, J., 1975. Advice to historians on advice to mothers. Journal of Social History 9, 44-63

NHS England 2016. Better Births. Improving outcomes of maternity services in England. A Five Year Forward view for maternity care. London: NHS England.

Nove A, Berrington A and Matthews Z 2008 Home births in the UK, 1955-2006. ONS Population

Trends 133: 20-27

Oakley A 1980 Women Confined: Towards a Sociology of Childbirth, Oxford: Martin Robertson Oakley A 1981 From here to maternity: becoming a mother. Penguin: Harmondsworth ONS [Office for National Statistics] 2016 Birth characteristics in England and Wales

https://www.ons.gov.uk/peoplepopulationandcommunity/birthsdeathsandmarriages/livebirths/bull etins/birthcharacteristicsinenglandandwales/2015

Petrovska K, Sheehan A and Homer GE 2017, Media Representations of breech birth: a prospective analysis of web-based news reports. Journal of Midwifery and Women's Health DOI:

10.1111/jmwh.120609

Seale C 2004 Health and the media Blackwell: Oxford

Song FW, West JE, Lundy L, Dahmen NS 2012 Women, pregnancy and health information online: the making of informed patients and ideal mothers. Gender and Society 26 (5): 773-798

Tew, M. 1995 Safer Childbirth? A Critical History of Maternity Care, $2^{\text {nd }}$ edn, London: Nelson Thornes Waddington, K. 2011. An introduction to the social history of medicine. Basingstoke: Palgrave Macmillan

Weaver J 2004 Caesarean section and maternal choices, Fetal and Maternal Medicine Review, 15 (1): 1-25

Wertz, R.W. and Wertz, D.C. 1989 Lying in: A History of Childbirth in America, $2^{\text {nd }}$ edn, Yale: Yale University Press

Williams G, Fahy K 2004 Whose interests are served by the portrayal of childbearing women in popular magazines for women. Am J Midwifery 17 (1): 11-16

Winship J 1987 Inside women's magazines. Pandora: London 